\title{
Análise das Metas do Plano Municipal de Educação de Quixadá-CE à Luz do PNE, da Legislação e do
} Documento Norteador

Antônio Jones Bezerra de Almeida

Sueli Maria de Araújo Cavalcante

Alberto Sampaio Lima

Linnik Israel Lima Teixeira

Universidade Federal do Ceará (UFC), Fortaleza/CE - Brasil

\section{Resumo}

O Plano Nacional de Educação se apresenta como um instrumento de planejamento que orienta a execução e o aprimoramento de políticas públicas do setor de educação. A presente pesquisa analisa o alcance das metas referentes ao ensino básico do Plano Municipal de Educação 20152025, sumarizando os dados obtidos do portal do Ministério da Educação (MEC), referentes às metas para o município de Quixadá, e contrastando os dados obtidos com dados equivalentes do Estado do Ceará e do âmbito Nacional. Utilizou-se o estudo de caso como método, cuja coleta de dados se fez por meio de acesso a documentos em sites oficiais via web. Considerando a relevância de todos os indicadores e sem prescindir da importância dos demais, destacam-se os indicadores da Meta 5 , pois representam pré-requisito a outros indicadores, estando relacionado à alfabetização, portanto à capacidade de entendimento daquilo que se lê, pelo fato de ser o meio para se aprender outras habilidades, ampliando a autonomia das pessoas com relação ao autoaprendizado e à educação continuada.

Palavras-chave: PNE. Plano Municipal de Educação. Avaliação Educacional.

\section{Analysis of the Goals of Quixadá-CE Municipal Education Plan Under the National Education Plan, the Legislation and the Guiding Document}

\section{Abstract}

The National Education Plan is presented as a planning instrument that guides the implementation and improvement of public policies in the education sector. This research analyzes the achievement of the 2015-2025 Municipal Education Plan goals related to K-12 education, summarizing the data obtained from the Ministry of Education (MEC) website, referring to the goals for the municipality of Quixadá-CE, and contrasting the data obtained from equivalent information from the State of Ceará and the national scope. The case study was used as a method and the data collection was accomplished through the access to documents in official websites. Considering the relevance of all the indicators and without disregarding the significance of the others, Goal 5 indicators stand out, as a prerequisite to other indicators, being related to literacy (i.e., the ability to understand what is read), since it is the way to learn other skills, increasing the autonomy of people concerning self-learning and continuing education.

Keywords: NEP. Municipal Education Plan. Educational Evaluation. 
Análise das Metas do Plano Municipal de Educação de Quixadá-CE à Luz do PNE, da Legislação e do Documento Norteador

\section{Introdução}

A presente pesquisa objetiva trazer uma abordagem e considerações sobre a Lei municipal $n^{\circ} 2.755$ de 19 de Junho de 2015 que aprova o Plano Municipal de Educação de Quixadá para o decênio de 2015-2025 e dá outras providências. Nela se buscarão dados sobre o alcance das metas propostas no Plano Municipal de Educação pelo município de Quixadá, considerando o ano de 2016, em comparação com as metas atingidas no âmbito Estadual e Nacional para o nível da Educação Básica.

As políticas públicas em educação correspondem aos meios de se dirimirem as desigualdades desenvolvidas pelas vantagens socioeconômicas, que acabam sendo interpretadas pela sociedade capitalista como méritos, acentuando as diferenças sociais e contribuindo para a perpetuação dos poderes econômicos e políticos, cujas manifestações se desalinham com o propósito social da educação. Para tanto, essas políticas buscam mitigar as diferenças de ordem socioeconômica, pedagógica, psicológica e cultural, contribuindo cada vez mais para a equidade na educação, ao contrário do que preceitua a teoria da meritocracia, termo cujo uso no campo educacional vem sendo cada vez mais frequente.

As agendas dos Fóruns Mundiais de Educação, por meio de líderes de centenas de países integrantes reafirmam a visão do movimento global "Educação para Todos", iniciado em Jomtien, em 1990, e reiterado em Dakar, em 2000, como o mais importante compromisso com a educação nas últimas décadas. No entanto, é nesse contexto estabelecido pela nova ordem mundial que a Educação, posta na representação do ensino público, é atacada por meio de medidas e estratégias privatizantes. É nesse arcabouço social, alicerçado e imposto por um sistema de economia de mercado, que se traduz em uma contrastante diferença na distribuição de renda, e que gera um imenso abismo cultural entre classes, que teremos o desenrolar de um conjunto de eventos que definem e/ou definirão as leis e as normas que regem o destino da Educação no Brasil e que, devido ao propósito neoliberal que assume, dificulta o estabelecimento de objetivos claros, definidos e práticos.

Nesse contexto, e prescindindo-se os objetivos reais velados nessas propostas, no início do século XXI, as políticas públicas de educação no Brasil têm dado margem a muitas discussões. O Compromisso Todos pela Educação, o Plano Nacional de Educação (PNE) e os Planos Estaduais e Municipais e as ações previstas no Plano de Desenvolvimento da Educação (PDE) deram origem a uma grande movimentação de projetos de ação educacional.

Torna-se imprescindível, portanto, que os resultados de tais ações de acompanhar, de avaliar, apresentem pressupostos concretos e passíveis de discussões para que as cobranças de efetividade dessas propostas sejam inequivocamente alinhadas com os verdadeiros propósitos das políticas públicas em Educação. A exigência dos direitos sociais, conscientemente respaldada, deve ser pressuposto do exercício da cidadania. Portanto, o presente trabalho aduz a uma pequena contribuição no sentido do conhecimento adquirido e oferecido sobre o tema, assim como, em consonância com os princípios da transparência pública, demonstra que o papel de cidadão esclarecido é exercido em sua plenitude.

O estudo que aqui se propõe se construirá em sete seções. A próxima seção dá um breve contexto político sobre a educação básica no Brasil. 


\title{
Educação Básica e um Mundo em Processo de Transformação
}

Para Dourado (2007), a concepção de educação é entendida como prática social, constitutiva e constituinte das relações sociais mais amplas, a partir de embates e processos em disputas que traduzem distintas concepções de homem, de mundo e de sociedade.

Em um olhar mais avançado sobre o conceito de educação básica e a significação que o tema ganhou, a Constituição Federal de 1988 (CF) criou as condições para que a LDB da Educação Nacional, 9.394/96 fundamentasse tal conceito - com base em uma abordagem que considera o pleno desenvolvimento do educando, seu preparo para o exercício da cidadania e sua qualificação para o trabalho, inspirada nos princípios de liberdade e nos ideais de solidariedade humana, devendo abranger os processos formativos que se desenvolvem em família, na convivência humana, no trabalho, nas instituições de ensino e pesquisa, nos movimentos sociais e organizações da sociedade civil e nas manifestações culturais.

Nesse sentido, Vieira (2001, p. 2800 apud OLIVEIRA, 2012, p. 10) considera que

\begin{abstract}
[...] em nenhuma Constituição brasileira a política social encontrou tamanho acolhimento como na de 1988 (artigos $6^{\circ}$ a 11), especificando: nos campos da Educação (préescolar, fundamental, nacional, ambiental etc.), da Saúde, da Assistência, da Previdência Social, do Trabalho, do Lazer, da Maternidade, da Infância, da Segurança, definindo especificamente direitos dos trabalhadores urbanos e rurais, da associação profissional ou sindical, de greve, da participação de trabalhadores e empregadores em colegiados dos órgãos públicos, da atuação de representante dos trabalhadores no entendimento direto com empregadores.
\end{abstract}

A despeito disso, o desencadear das consequências advindas da aplicação das leis voltadas à Educação tem sido o background de muitas discussões políticas e acadêmicas, cujos resultados obrigam os principais stakeholders (os educandos) a receberem um serviço pautado em critérios nos quais, muitas vezes, os próprios educandos não são os verdadeiros protagonistas ou os principais beneficiários.

Cabe aqui ainda uma reflexão sobre qual o sentido da Educação e das políticas públicas da educação básica, à luz das questões postas à educação por um cenário político em transformação, no qual as mudanças tendem a desestruturar toda e qualquer ação voltada ao social. Considere-se aqui que, no momento em que este trabalho é construído, há se consumado "[...] um processo de gravíssima ruptura democrática no país, [...] representando um risco sem precedentes aos direitos sociais, educacionais e de cidadania" (EDITORES, 2016, p. 329) conquistados após o regime da força. Editores (2016, p. 330) corrobora, asseverando que:

No desmonte anunciado das políticas sociais voltadas aos setores populares, [...] a limitação de gastos impedirá o cumprimento das metas estabelecidas no Plano Nacional de Educação (PNE), entre elas e, sobretudo, a efetivação da educação obrigatória para todos os jovens entre 4 e 17 anos, o estabelecimento do CAQ/CAQI (Custo aluno qualidade/Custo aluno qualidade inicial) e a valorização do magistério da educação básica como política obrigatória em todo o território nacional.

Não obstante os infortúnios praticados pelo interino e ilegítimo governo e das perspectivas preocupantes para o futuro da Educação do País (EDITORES, 2016, p. 330 e 334), Dourado (2007) assevera que: 
[...] a articulação e a rediscussão de diferentes ações e programas, direcionados à gestão educacional, devem ter por norte uma concepção ampla de gestão que considere a centralidade das políticas educacionais e dos projetos pedagógicos das escolas, bem como a implementação de processos de participação e decisão nessas instâncias, balizados pelo resgate do direito social à educação e à escola, pela implementação da autonomia nesses espaços sociais e, ainda, pela efetiva articulação com os projetos de gestão do MEC, das secretarias, com os projetos político-pedagógicos das escolas e com o amplo envolvimento da sociedade civil organizada.

Frigotto e Ciavatta (2003) aludem à ocorrência de uma disputa entre o ajuste dos sistemas educacionais às demandas da nova ordem do capital e as demandas por uma efetiva democratização do acesso ao conhecimento em todos os seus níveis. Para Blasques (2016, p. 4), a educação ocupa um lugar de interesses crescentes, mobilizando organizações e autoridades globais em prol da equidade e qualidade de aprendizagem e o exercício de uma cidadania plena. Nesse contexto, destacam-se eventos como a "Conferência Mundial sobre "Educação para Todos" realizada em Jomtien, Tailândia, em 1990, e que, em 2000, no Fórum Mundial de Educação em Dakar, Senegal, 164 governos concordaram com o Marco de Ação de Dakar, "Educação para Todos: Cumprindo nossos Compromissos Coletivos", que lançou uma agenda ambiciosa para alcançar seis objetivos educacionais de amplo alcance até 2015. Em 2015, em resposta, a UNESCO iniciou os Relatórios de Monitoramento de EPT, para monitorar o progresso, destacar lacunas persistentes e fazer recomendações para a agenda global de desenvolvimento sustentável pós-2015 (UNESCO, 2015, p. 3).

A UNESCO, junto com o Fundo das Nações Unidas para a Infância (UNICEF), o Banco Mundial, o Fundo de População das Nações Unidas (UNFPA), o Programa das Nações Unidas para o Desenvolvimento (PNUD), a ONU Mulheres e o Alto Comissariado das Nações Unidas para Refugiados (ACNUR), organizaram o Fórum Mundial de Educação 2015, em Incheon, na Coreia do Sul, em maio de 2015. Mais de 1.600 participantes de 160 países, incluindo mais de 120 ministros, chefes e membros de delegações, líderes de agências e funcionários de organizações multilaterais e bilaterais, além de representantes da sociedade civil, da profissão docente, do movimento jovem e do setor privado adotaram a Declaração de Incheon para a Educação 2030, que estabelece uma nova visão para a educação nos próximos 15 anos (UNESCO, 2016).

Höfling (2001, p. 34) ratifica os pensamentos de Frigotto e Ciavatta (2003) e Blasques (2016), em que Claus Offe se aporta à concorrência de "[...] fatores advindos de diferentes esferas e organismos da sociedade, em seu conjunto, para a gênese e desenvolvimento do Estado":

Respondendo a uma pergunta sobre um 'novo pacto social', o autor assinala que 'os problemas de um país não vão ser resolvidos apenas pela ação do Estado ou do mercado. É preciso um novo pacto, que resolve o dever do Estado de dar condições básicas de cidadania, garanta a liberdade do mercado e da competição' (HÖFLING, 2001).

Embora sejam os mesmos os objetivos instaurados nos países desenvolvidos, as consequências são bem distintas, bem como as possibilidades de implantação do projeto neoliberal: com uma classe trabalhadora organizada e protegida por um efetivo "Estado do Bem-Estar-Comum", os limites neoliberais logo aparecem.

Em tal contexto estabelecido pela nova ordem mundial, a Educação pública é atacada por meio de medidas e estratégias privatizantes, impostas por um sistema de economia de 
mercado, que se traduz em diferenças na distribuição de renda, o que gera um imenso abismo cultural entre classes e desenrola um conjunto de eventos que têm definido as leis e as normas que atualmente determinam o destino da Educação no Brasil. Devido ao propósito neoliberal que assume, esse Ensino Básico padece de um grave problema de financiamento, em que os discursos de um estado ineficiente e caro reduzem-se aos recursos dirigidos à Educação.

\section{PNE E PME - da lei à elaboração}

A redação dada pela Constituição de 1988, no art. 214 da Carta Magna, previu a implantação legal do Plano Nacional de Educação. A Emenda Constitucional (EC) n 59/2009 requalificou o papel do $\mathrm{PNE}$, garantindo os direitos da população, preceituada pela $\mathrm{CF}$, em seus Artigos 205 e 206 e incisos I a VII (preceituando a Educação como um direito de todos e definindo suas e bases e princípios), e na LDB $n^{\circ}$ 9.394/96. Foi, então, sancionada, e sem vetos, a Lei $n^{\circ} 13.005$, de 25 de junho de 2014, que fez entrar em vigor o Plano Nacional de Educação (PNE) 2014-2024 - o segundo PNE aprovado por lei.

O Plano Nacional de Educação (PNE), Lei no 13.005/2014, se apresenta como um instrumento de planejamento que orienta a execução e o aprimoramento de políticas públicas do setor. Nesse PNE, fruto de amplos debates entre diversos atores sociais e o poder público, estão definidos os objetivos e metas para o ensino em todos os níveis - infantil, básico e superior - a serem executados nos próximos dez anos.

O PNE 2014-2024 traz dez diretrizes, entre elas a erradicação do analfabetismo, a melhoria da qualidade da educação, além da valorização dos profissionais de educação, um dos maiores desafios das políticas educacionais. De acordo com o art. $7^{\circ}$ dessa nova lei, a União, os estados, o Distrito Federal e os municípios atuarão em regime de colaboração para atingir as metas e implementar as estratégias previstas no texto.

O assunto requeria uma ampla e exaustiva discussão, com aprofundado trabalho de planejamento, elemento imprescindível na elaboração de Planos de Educação, como propõe Vianna (2005, p. 103) ao afirmar que "[...] o impacto de um projeto traduz-se por criar novas atitudes, gerar novos conhecimentos e influenciar novas formas de pensar", não obstante, 0 PNE foi encaminhado para a participação social no debate e, nas audiências públicas, foram convidados e ouvidos autoridades e técnicos vinculados às posições oficiais.

Corroborando a necessidade da ampla discussão pública do tema, Vianna (2005, p. 104) argumenta que:

Um bom planejamento da avaliação dá-nos certeza de que as várias audiências a que o trabalho se destina compreenderão os resultados apresentados; que as informações proporcionadas serão vistas com credibilidade, inclusive por públicos não especializados; que as questões levantadas foram relevantes e adequadamente respondidas pela avaliação; e que novos posicionamentos, refletindo atitudes positivas, surgirão em decorrência da avaliação.

A despeito disso, após ser encaminhado para uma brevíssima participação social no debate, o Plano foi aprovado.

Destarte, o meio político movimentou discussões voltadas à educação, impulsionando novos financiamentos e mecanismos de avaliação e exigências em estratégias de melhoria da educação básica praticada pelos entes federados, em sistemas cooperados. 
Particularmente em torno da educação básica, projetos são debatidos para a garantia e concretização da equidade no oferecimento da Educação Básica e da Educação Superior, elaboram-se propostas de políticas globais para valorização dos trabalhadores em educação: Plano Nacional de Educação (PNE) e os Planos Estaduais e Municipais, as ações previstas no Plano de Desenvolvimento da Educação (PDE), o Compromisso Todos pela Educação deram origem a uma grande movimentação de projetos de ação educacional.

Assim, o Plano Nacional de Educação, de duração decenal, tem o objetivo de articular o sistema nacional de educação em regime de colaboração e estabelece diretrizes, objetivos, metas e estratégias de implementação para assegurar a manutenção e desenvolvimento do ensino em seus diversos níveis, etapas e modalidades por meio de ações integradas dos poderes públicos das diferentes esferas federativas, que conduziriam a: I - erradicação do analfabetismo; II - universalização do atendimento escolar; III - melhoria da qualidade do ensino; IV - formação para o trabalho; V - promoção humanística, científica e tecnológica do País. VI - estabelecimento de meta de aplicação de recursos públicos em educação como proporção do produto interno bruto (BRASIL, 2014b). Considere-se, nesse contexto, Esferas Federativas, segundo Hentz (2014), o que pertence às competências de uma das esferas do poder político: o poder federal, o qual deve se submeter, tanto quanto estados e municípios, às determinações com caráter nacional.

Esse tópico constitucional balizou a Lei $n^{0} 13.005$, de 25 de junho de 2014, que aprovou - Plano Nacional de Educação - PNE, cujas diretrizes contemplaram, além das ações propostas na CF de 1988, a superação das desigualdades educacionais, com ênfase na promoção da cidadania e na erradicação de todas as formas de discriminação; a formação para o trabalho e para a cidadania, com ênfase nos valores morais e éticos em que se fundamenta a sociedade; a promoção do princípio da gestão democrática da educação pública; o estabelecimento de meta de aplicação de recursos públicos em educação como proporção do Produto Interno Bruto - PIB, que assegure atendimento às necessidades de expansão, com padrão de qualidade e equidade; a valorização dos (as) profissionais da educação e a promoção dos princípios do respeito aos direitos humanos, à diversidade e à sustentabilidade socioambiental (BRASIL, 1988).

Com o intuito de prover a aplicabilidade das metas previstas no PNE, a referida Lei ainda prevê em seu Artigo $4^{\circ}$ a Pesquisa Nacional por Amostra de Domicílios - PNAD, o censo demográfico e os censos nacionais da educação básica e superior como embasamento estatístico e de referência (BRASIL, 2014a).

Com a aprovação da Lei $n^{\circ} 13.005$, de 25 de junho de 2014, o Plano de Ações Articuladas (PAR), que tinha a missão de identificar e solucionar problemas que afetavam a Educação Básica no país e visava à sua qualidade, em todos os níveis e modalidades, no prazo de 15 anos, a contar da publicação do decreto, "[...] deixa de limitar-se ao Plano de Metas Compromisso Todos pela Educação, passando a observar as metas, diretrizes e estratégias dos Planos Nacionais de Educação (PNEs)" (SOUZA; BATISTA, 2016, p. 107).

Hentz (2014, p. 135) alude ao tema e enfatiza que

[...] o artigo $8^{\circ}$ dessa Lei determina ainda que os Estados e os Municípios tenham aprovado, no prazo de um ano, seus próprios planos de educação, e que é relevante que a elaboração e a aprovação desses planos sejam procedidas com todo o rigor analítico e propositivo, para que não se limitem ao cumprimento de uma determinação 
legal, mas que resultem em planos de educação que sejam, ao mesmo tempo, factíveis e ousados, considerando diagnósticos confiáveis, bem como metas e estratégias que tenham o potencial de elevar o patamar da qualidade geral da educação no Brasil.

Bandeira et al. (2013) corroboram, afirmando que os Planos devem ser construídos para um território (município ou estado), envolvendo todo o atendimento educacional nele existente, não devendo se restringir ao atendimento da rede municipal de ensino, mas deve levar em conta o conjunto da Educação Básica e do Ensino Superior de seu território. Por isso, a construção de um Plano de Educação deve mobilizar a colaboração entre os entes federados (município, estado e União) e considerar também o atendimento realizado por instituições privadas. Tal ideia é ainda reforçada por Valle (2009, p. 3), ao afirmar que:

Na construção democrática da sociedade, os planos devem ser elaborados pelo conjunto da sociedade e pelo Poder Público (nacional, estadual, municipal) fixando objetivos, diretrizes e metas para todos os níveis e modalidades de ensino. Seu objetivo maior então é o de garantir aos cidadãos que a educação escolar, enquanto política social, direito de todos e um dever indeclinável do Estado, seja oferecida com qualidade, permitindo assim o acesso e a permanência do conjunto da população à escola. Várias, entretanto, podem ser as formas para a sua elaboração e materialidade. Deste modo, ora são gestionados de forma mais democrática - garantindo os processos participativos, ora por comissões criadas pelo Poder Político.

Assim, a regionalização da construção dos planos por meio da delegação de sua elaboração aos municípios e estados, como se delineia no supracitado artigo, possibilita uma maior articulação entre as comunidades locais, permitindo a construção de um Plano de Ensino devidamente alinhado à realidade e aos anseios da comunidade que o recebe em execução.

Diante do exposto, denota-se que o trabalho de elaboração do Plano Municipal de Educação pode se deparar com obstáculos: falta de dados estatísticos disponíveis e precisos; escassez de tempo e limitação de pessoal, no entanto, tais dificuldades poderão ser facilmente superadas, com a devida decisão política e técnica (BRASIL, 2005), uma vez que, segundo Vianna (2005, p. 40), "[...] a eficiência de um governo não está no fazer, mas no saber fazer em correspondência com as realidades vividas no contexto da sociedade".

A seção seguinte apresenta um documento elaborado pela Secretaria de Educação Básica do Ministério da Educação, com o intuito de "estimular e apoiar os sistemas de ensino quanto à formulação e à avaliação coletiva de planos nacionais, estaduais e municipais de educação" e nortear os trabalhos, oportunizando aos municípios o planejamento e execução de suas ações a partir de informações da situação educacional.

\section{O documento norteador para elaboração de Plano Municipal de Educação - PME}

Apresentado como uma contribuição que se soma aos esforços da União Nacional dos Dirigentes Municipais de Educação - Undime, da União Nacional dos Conselhos Municipais de Educação - UNCME e do Fundo das Nações Unidas para a Infância - Unicef, no trabalho permanente e constante de incentivar os dirigentes municipais de educação na afirmação da importância e da necessidade dos municípios elaborarem seus Planos Municipais de Educação e objetivando a organização e o fortalecimento dos sistemas de ensino, de modo geral, o Documento Norteador para Elaboração de Plano Municipal de Educação - PME 
estimula e apoia os sistemas de ensino quanto à formulação e à avaliação coletiva de seus planos nacionais, estaduais e municipais de educação e norteia os trabalhos, oportunizando aos municípios o planejamento e execução de suas ações a partir de informações da situação educacional.

O documento define dois princípios norteadores do processo de elaboração dos planos: o princípio da gestão democrática da Educação, onde a elaboração do PME deve observar o princípio constitucional de "gestão democrática do ensino público" (C.F. art. 206, inciso VI), e o espírito e as normas definidas no Plano Nacional de Educação estabelecidas na Lei $n^{\circ}$ 10.172, de 09 de janeiro de 2001; e os princípios da autonomia e da colaboração, posto que o PNE foi balizado por dois princípios constitucionais: autonomia dos entes federados e o regime de colaboração. A aplicação de um princípio requer a colaboração do outro, para que os propósitos da educação, que são de todos, sejam respeitados no espaço próprio de cada ente federativo. Nessa perspectiva, são atribuídas responsabilidades comuns e outras da realização prioritária por um ou mais entes federativos, cuja execução depende de colaboração de todos.

O Documento Norteador para Elaboração de Plano Municipal de Educação - PME apresenta em seu capítulo 3 uma relação de entidades sugeridas para contribuições na elaboração do documento, asseverando que

[...] é importante que na elaboração de seu PME, os gestores desenvolvam ações que garantam um amplo processo democrático de participação, envolvendo os diferentes atores que, de forma direta ou indireta, influenciam na qualidade da educação do Município. Sugere-se a participação do Poder Executivo, o Poder Legislativo, o Ministério Público e a Sociedade Civil Organizada (BRASIL, 2005, online).

Mais uma vez aqui se define a necessidade da ampla participação de todos os setores da sociedade e de seus representantes, reforçando a lembrança de Hentz (2014) ao afirmar que "[...] o processo histórico que a nação brasileira construiu desde 1985, com o fim do último regime de força e o início da reconstrução da democracia, tem sido marcado até o presente por uma crescente consolidação democrática".

\section{Acompanhamento e Avaliação}

O Plano Municipal deve prever e determinar os momentos estratégicos para realizar uma avaliação das ações e das atividades que estão sendo desenvolvidas e analisar os resultados que estão sendo alcançados com o objetivo de poder redirecionar as estratégias de execução.

Dessa forma, é importante elaborar alguns instrumentos que sirvam não apenas para realizar o acompanhamento das ações, como também para avaliar os resultados alcançados e realimentar a dinâmica do processo executivo do Plano. Nessa perspectiva, é fundamental que, concluída a tramitação e aprovada a lei do PME, se constitua um fórum permanente para seu acompanhamento e avaliação. Andriola (1999, p. 364) esclarece que se faz "[...] necessário reconhecer que somente através da investigação se pode obter uma base valiosa de dados que proporcionem reflexões úteis para todos aqueles envolvidos no objetivo do melhoramento da educação". O autor (1999, p. 364) ainda assevera que

[...] a inevitabilidade de avaliação parte da necessidade de averiguação dos resultados propostos nos objetivos planejados pelas instituições de ensino, no cumprimento de seu 
papel social ou objetivos diferenciados, seja em instituições públicas ou privadas, para que esses resultados avaliativos possam vir a revelar falhas ou virtudes no funcionamento da instituição, fundamentando o processo avaliativo, como instrumento de qualquer mudança que se queira empreender com a garantia de Êxito.

Nesse contexto, a atividade avaliadora deve tomar parte de um processo mais geral de cunho social, que persiga a melhora da qualidade de vida de cada comunidade escolar, assim como fomentar o desenvolvimento profissional e a investigação avaliativa.

Como propõe Vianna (2005, p. 100), ao asseverar que

A avaliação visa à tomada de decisões para melhorar o que já existe, seja por intermédio de alterações, a fim de corrigir possíveis distorções, seja através de acréscimos, suprindo prováveis omissões. Tudo isso deve ser, necessariamente, objeto de consideração da equipe na fase de planejamento de um projeto e na sua execução.

Desse modo, a avaliação é entendida como uma atividade basicamente valorativa e de pesquisa e, portanto, facilita a mudança educacional e o desenvolvimento profissional de professores. Ela afeta não só os processos de aprendizagem dos alunos, mas também os processos de ensino desenvolvidos por professores e projetos curriculares. A avaliação é, assim, o elemento-chave para orientar as decisões curriculares, definir os problemas educacionais, empreender ações concretas, para realizar processos de pesquisa em educação, geração dinâmica de formação de professores e, em última instância, para regularizar o processo de adaptação e contextualização do currículo em cada comunidade escolar.

O processo de avaliação deve, portanto, ser principalmente um processo qualitativo e explicativo, fornecendo dados quantitativos e interpretações significativas que permitam compreender e apreciar os processos seguidos por todos os participantes.

Na seção seguinte serão delineados aportes sobre o conceito de indicadores e recortes temporais e documentais sobre a elaboração do PME.

\section{Características gerais do município}

Distante $167 \mathrm{~km}$ da capital do estado do Ceará (147 km em linha reta), o município de Quixadá é constituído de 13 distritos: Quixadá (Sede), Califórnia, Cipó dos Anjos, Custódio, Daniel de Queiróz, Dom Maurício, Juá, Juatama, Riacho Verde, São Bernardo, São João dos Queirozes, Tapuiará e Várzea da Onça. Assim permanecendo em divisão territorial datada de 2015. Localiza-se na macrorregião de planejamento Sertão Central, na mesorregião dos Sertões Cearenses e na microrregião do Sertão de Quixeramobim. É a maior cidade do sertão central, segundo o Instituto Brasileiro de Geografia e Estatística (IBGE), sua população é 80.604 habitantes (em dados de 2010 ), sendo $71,32 \%$ residentes na zona urbana; sua área de unidade territorial, em dados de 2015 , é de $2.019,833 \mathrm{~km}^{2}$ e sua densidade demográfica, em dados de 2010, de 39,91 hab/m². A estimativa populacional para 2016 é de 85.991 pessoas, segundo o IBGE. O município de Quixadá possui o $17^{\circ}$ maior PIB do estado e Índice de Desenvolvimento Humano (IDH - 2010) de 0,659, ocupando o $14^{\circ}$ no ranking do estado, e um Índice de Desenvolvimento Municipal (IDM - 2012) de 34,92, ocupando a $45^{\circ}$ posição no ranking do estado (BRASIL; IBGE, 2013; CEARÁ, 2015).

Ainda, segundo dados de Ceará (2015), o município de Quixadá possui uma escola da rede Federal (contemplando ensino médio, técnico e superior), 07 Escolas Estaduais, 61 
Análise das Metas do Plano Municipal de Educação de Quixadá-CE à Luz do PNE, da Legislação e do Documento Norteador

Escolas municipais e 15 escolas Particulares. Considerada uma cidade Universitária, dispõe de 06 Instituições de Ensino Superior (IES), sendo duas Instituições Federais, uma Instituição Estadual e três IES privadas.

Características econômicas pormenorizadas não foram aqui abordadas, devido ao fato de o objetivo do trabalho prescindir de tais dados.

\section{Construção do PME de Quixadá}

Considerados os passos iniciais para o processo de formulação do Plano Municipal de Educação de Quixadá, ambas de 10 de Setembro de 2013, a Portaria 001/2013, que cria o Fórum Municipal de Educação para coordenar a elaboração do Plano Municipal de Educação de Quixadá e dá outras providências (QUIXADÁ, 2013a), e a Portaria 002/2013, que nomeia a comissão do Plano Municipal de Educação para o decênio "2015 a 2015" [sic] e dá outras providências (QUIXADÁ, 2013b), tais decisões normativas se encontram previstas, na forma de orientações, no Documento Norteador para Elaboração de Plano Municipal de Educação - PME, Brasil (2005, p. 24, grifo nosso), cujo teor propõe que

\footnotetext{
Um processo participativo bem conduzido fará com que todos se envolvam e o resultado seja o produto pelo qual a sociedade deve sentir-se corresponsável. As formas de execução, a depender de cada caso, podem ser escolhidas entre as diversas modalidades de trabalhar: a criação de um fórum, de uma comissão, de um conselho (se existir o Conselho Municipal de Educação, este poderá ser o articulador), ou de um colegiado para planejar o processo e coordenar as reuniões e os debates, reunir as sugestões e redigir os textos a serem submetidos às diversas instâncias.
}

Assim, municípios que ainda não possuíam seus planos de educação, a partir da publicação da referida lei deveriam, no prazo de um ano, elaborá-los. Os municípios que possuíam plano, nesse período de um ano deveriam fazer as adequações. Após a articulação contemplando o Artigo $9^{\circ}$ da Lei $n^{\circ} 13.005$ de junho de 2014, os municípios deveriam aprovar leis para disciplinar a gestão democrática. O Plano Municipal de Educação deveria passar pela Câmara de Vereadores como projeto, criando uma lei específica para o plano, que deveria ser sancionada pelo Governo Municipal.

Em 30 de Julho de 2014, por meio da Portaria n 35/2014, a Secretaria Municipal de Educação de Quixadá instituiu a Comissão Representativa da Sociedade para Elaboração/Adequação do Plano Municipal de Educação do Município de Quixadá-CE (QUIXADÁ, 2014). Foi definida, em seu Artigo $2^{\circ}$, a responsabilidade dessa comissão pela elaboração/adequação do PME, cuja sanção se dera em data anterior. Em seu artigo $3^{\circ}$, versa sobre a participação democrática, transparente e reflexiva e sobre as necessidades e demandas da educação no município, impactando na qualidade e na garantia do direito à educação, legitimada pelas forças sociais e políticas (QUIXADÁ, 2014).

A Portaria de Gabinete $n^{\circ} 35 / 2014$, ainda estabelece, em seu Artigo $4^{\circ}$, a composição da Comissão Representativa da Sociedade, definindo inicialmente sua formação a partir de um membro titular e um suplente dos seguintes órgãos: Câmara Municipal de Quixadá, Conselho Municipal de Educação - CMEQ, Universidade Federal do Ceará - UFC, Faculdade de Educação Ciências e Letras do Sertão Central - FECLESC, Universidade Aberta do Brasil - UAB - Polo de Quixadá, Instituto Federal do Ceará - IFCe - Campus Quixadá, Coordenadoria Regional de Desenvolvimento da Educação - CREDE 12, Escola de Ensino Médio Coronel 
Virgílio Távora, Sindicato dos Servidores Públicos Municipais - SINDSEP, Representantes Estudantis, Representantes de Pais, Equipe técnica (responsáveis pelo Censo Escolar, pelo PAR e pela Administração e Planejamento da Secretaria Municipal de Educação).

As atribuições dessa comissão, estabelecidas pelo Artigo $5^{\circ}$ da Portaria Gabinete $n^{\circ}$ 35/2014 são: i) Sensibilizar a sociedade da necessidade de adequação do PME; ii) Realizar Análise técnica e política da situação educacional do município e a proposta do texto base do PME, elaborado pela comissão técnica instituída pela Secretaria Municipal de Educação; iii) Organizar Consulta Pública sobre a proposta do PME de Quixadá; iv) Encaminhar ao Poder Executivo; v) Acompanhar, junto ao Poder Legislativo, a tramitação e aprovação do PME.

Em 17 de Junho de 2015, a Câmara Municipal de Quixadá, conduzida pelo Presidente da casa Legislativa do Município de Quixadá, discutiu em sessão extraordinária as novas diretrizes do PME - Plano Municipal de Educação de Quixadá, decênio 2015।2025, projeto do executivo de $n^{\circ} 23 \backslash 2015$. O debate contou com a participação efetiva da Presidente do CME - Conselho Municipal de Educação, dos profissionais da educação de Quixadá, com a presidente do SINDSEP - Sindicato dos Servidores Públicos Municipais e da coordenadora geral do PMEQ, que fez a apresentação da proposta educacional e de todo o processo realizado para sua formulação, e de convidados.

Em relação à definição de prazos e previsões de datas, novamente reporta-se aqui ao documento "Plano Nacional de Educação - PNE - 2014-2024: linha de base" para um delineamento do contexto de elaboração do PME em função do que nele se estabelece, que:

Tendo em conta essa Linha de Base para o diagnóstico dos aspectos circunscritos no PNE acerca da educação brasileira, o processo de monitoramento do Plano será contínuo e contará com um cronograma para o desenvolvimento e a publicação bienal dos estudos que devem ser feitos pelo Inep [...] (BRASIL, 2015, p. 16).

Enfatiza-se que, ao ser elaborado, o Plano Municipal de Educação deve ter suas bases construtivas conduzidas em três etapas e passos consequentes: Elaboração do Plano Municipal de Educação; A Implantação do Plano Municipal de Educação; Acompanhamento e Avaliação do Plano Municipal de Educação (BRASIL, 2005). Assim, sancionada pelo Prefeito Municipal de Quixadá, em 19 de Julho de 2015, a Lei n 2755 implantou em Quixadá o seu Plano Municipal de Educação para o decênio 2015 a 2025, estabelecendo o que se prevê nas duas primeiras etapas e passos propostos pelo Documento Norteador do PME. A fase seguinte de Acompanhamento e Avaliação do PME, previstas no cronograma da Figura 1, deverão ter suas atividades encaminhadas a partir da gestão do Prefeito Eleito, em 2016, para a próxima gestão, diante da liberação dos dados para aferição das Metas do PNE, previstas para 2016.

\section{PME e o controle dos resultados e do alcance das metas}

O processo de avaliação envolve uma classificação final ou, ao longo do processo avaliativo, expressa, em notas escolares, diplomas e certificados, que atestem que o aluno é ou não é instruído na aprendizagem a que se propôs o Plano.

Tradicionalmente, a valoração do aproveitamento era a única finalidade da avaliação. No entanto, isso não é suficiente, uma avaliação contínua implica um novo conceito de desempenho focado na orientação correta do estudante, e um retorno da eficiência do Plano em execução. 
Admitir a função de controle que as avaliações realizam não significa que se está confundindo avaliação com qualificação. O processo de avaliação pressupõe que se integrem todos os dados que se têm sobre os estudantes, e os ponha em contraste, ou comparação com os objetivos propostos pelo Estado.

O Art. $6^{\circ}$ do PME prevê o contínuo e periódico monitoramento da execução e do cumprimento das metas nele estabelecidas. Em seu parágrafo $3^{\circ}$, esse artigo ainda prevê que, ao longo da vigência do PME, a Secretaria Municipal de Educação do Município, em parceria com o Conselho Municipal de Educação de Quixadá - CMEQ, realizará estudos para aferir a evolução do cumprimento das metas estabelecidas no PME, tendo como referência os estudos e as pesquisas de que trata o Art. $5^{\circ}$, sem prejuízo de outras fontes e informações relevantes, como, por exemplo, o que prevê o Artigo $12^{\circ}$ cujo teor propõe que o Sistema Nacional de Avaliação da Educação Básica (SAEB), coordenado pela União, em colaboração com os Estados, o Distrito Federal e os Municípios, e o Sistema de Avaliação Educacional de Quixadá - SAEQ constituirão fontes de informação para a avaliação da qualidade da educação básica e para a orientação das políticas públicas do Município.

O Artigo $7^{\circ}$ incumbe a Secretaria Municipal de Educação de promover e realizar pelo menos três conferências municipais até o final da década, estipulada no artigo $1^{\circ}$ para 2025 , com intervalos de três anos ente elas, objetivando avaliar e monitorar a execução das metas que deverão ser implementadas durante a execução do Plano Municipal de Educação - PME, e subsidiar a elaboração do Plano Nacional de Educação para o próximo decênio.

\section{Procedimentos Metodológicos}

Segundo Yin (2010), como esforço de pesquisa, o estudo de caso contribui, de forma inigualável, para a compreensão que temos dos fenômenos individuais, organizacionais, sociais e políticos.

Contextualizando com as ideias de Yin (2010), temos, por analogia, que o escopo proposto na pesquisa abordará "o que" a Secretaria Municipal de Educação de Quixadá e Poder Executivo fizeram - construção e elaboração conjunta - do Plano Municipal de Educação segundo a Proposta do Plano Nacional de Educação. Nesse sentido, os objetivos se comporão a partir do "como" ou "por que" o programa se fundamentou para sua criação e como ocorreu a participação dos atores responsáveis pela elaboração do Plano, definindo-se assim, reforçado por Schramm (1971, apud YIN, 2010), a essência de um estudo de caso, tratando-se, portanto, [...] de uma investigação empírica que se reporta a um fenômeno contemporâneo, dentro de seu contexto da vida real, especialmente quando os limites entre o fenômeno e o contexto não estão claramente definidos (YIN, 2010).

Ao longo da pesquisa foram levantadas, como fontes bibliográficas, publicações - livros, teses, monografias, publicações avulsas e pesquisas que forneceram o conjunto teórico e cuja busca se desenvolveu em quatro fases: identificação, localização, compilação e fichamento, segundo Marconi e Lakatos (2010).

Por se tratar de um estudo sobre uma lei municipal, implementada em uma unidade da Federação, foram também consultados documentos oficiais disponibilizados nos portais oficiais da UNESCO, do MEC, do IBGE, da Secretaria de Educação do Estado do Ceará, da Prefeitura Municipal de Quixadá, da Câmara Municipal de Quixadá e da Secretaria Municipal de Educação de Quixadá. Foram trazidos, à luz da pesquisa, as Portarias 001/2013, 
002/2013, 035/2014 e a Lei municipal do Plano Municipal de Educação, todos os materiais para caracterização do Município e suas ações no âmbito da Educação Básica se encontravam disponíveis na Internet.

Os dados consolidados, até a data de 08 de dezembro de 2016, referentes ao alcance (ou insucesso do alcance) das metas do Plano Municipal de Educação para o Município de Quixadá, foram obtidos a partir do sítio (sistema) interativo "PNE em Movimento" do Portal do Ministério da Educação - MEC, cujo endereço "não encurtado" de acesso é: $<$ http://simec.mec.gov.br/pde/graficopne.php>.

A página disponibiliza uma seção com quatro caixas de seleção, referentes a quatro Níveis Geopolíticos: Região, Estado, Mesorregião e Município, e uma sequência de 20 "abas", referentes às 20 metas estabelecidas no PNE e propostas à execução aos Entes Federados, segundo Hentz (2014). Para o objetivo proposto, procedeu-se a seguinte seleção: Estado: <Ceará>; Cidade: <Quixadá>; Aba: <Foram selecionadas as 20 abas, uma a uma e sucessivamente, para cada uma das metas do PME>. A meta apresentada para o "Brasil", bem como seu desempenho atingido até o momento, já aparece, independente de que uma seleção the seja auferida. Para esse procedimento, optou-se por não auferir valores nas caixas de seleção "Região" e "Mesorregião". Os dados foram posteriormente agrupados em um quadro resumo.

Diante do que foi até aqui proposto como procedimentos metodológicos, pode-se depreender que o trabalho se apresenta como uma pesquisa básica, quanto à natureza, segundo Prodanov e Freitas (2013), também chamada de pesquisa empírica, pois o pesquisador se dedica a codificar a face mensurável da realidade social, indo a campo, aqui expressado por meio da pesquisa via web. E, quanto à abordagem do problema, ela é quantitativa. Classifica-se ainda, segundo Gil (2010), Prodanov e Freitas (2013), Marconi e Lakatos (2010), quanto ao objeto de estudo, em descritiva, uma vez que expõe as características de uma determinada população ou fenômeno, demandando técnicas padronizadas de coleta de dados. E, como já defendido no início desta seção, delineado por Yin (2010), denota um estudo de caso, quanto aos procedimentos.

\section{Resultados e Discussão}

O MEC reuniu as 20 metas em quatro grupos principais, conforme seu foco de atuação: Grupo 1 - Metas estruturantes para a garantia do direito à educação básica com qualidade: Meta 1, Meta 2, Meta 3, Meta 5, Meta 6, Meta 7, Meta 9, Meta 10, Meta 11; Grupo 2 - Metas voltadas à redução das desigualdades e à valorização da diversidade: Meta 4 e Meta 8; Grupo 3: Metas para a valorização dos profissionais da educação: Meta 15, Meta 16, Meta 17 e Meta 18; Grupo 4 - Metas referentes ao ensino superior: Meta 12, Meta 13 e Meta 14 (BRASIL, 2015).

Não menos importantes, porém não incorporadas aos grupos citados anteriormente, as metas 19 e 20 estabelecem meios para consecução dos objetivos traçados pelas metas 1 a 18, estando presentes como outros grandes desafios, como o fortalecimento da gestão democrática, com leis específicas que a normatizem em cada rede ou sistema de ensino, tidos como elementos imprescindíveis do Sistema Nacional de Educação a ser instituído (BRASIL, 2014b). 
Os dados referentes aos grupos 2, 3 e 4 não serão aqui discutidos, em vista de serem prescindíveis aos objetivos do trabalho e oferecerem subsídios para trabalhos futuros.

Os dados das metas do Grupo 1 foram compilados e se encontram resumidos no quadro 1 , a seguir.

\section{Quadro 1 - Grupo 1 - Metas estruturantes para a garantia do direito à educação básica com} qualidade

\begin{tabular}{|c|c|c|c|c|c|c|c|}
\hline \multirow[b]{2}{*}{ META } & \multirow[b]{2}{*}{ Indicador } & \multicolumn{2}{|c|}{ Brasil } & \multicolumn{2}{|c|}{ Ceará } & \multicolumn{2}{|c|}{ Quixadá } \\
\hline & & Previsto & $\begin{array}{c}\text { Situação } \\
\text { atual }\end{array}$ & Previsto & $\begin{array}{c}\text { Situação } \\
\text { atual }\end{array}$ & Previsto & $\begin{array}{c}\text { Situação } \\
\text { atual }\end{array}$ \\
\hline \multirow{2}{*}{ Meta 1} & $1 \mathrm{~A}$ & 100 & 81,4 & 93 & 93 & 100 & 91 \\
\hline & $1 \mathrm{~B}$ & 50 & 23,2 & 50 & 22,1 & 50 & 28,2 \\
\hline \multirow{2}{*}{ Meta 2} & $2 \mathrm{~A}$ & 100 & 98,4 & 100 & 98,8 & 100 & 95,8 \\
\hline & $2 \mathrm{~B}$ & 95 & 66,7 & 95 & 64,5 & 95 & 71,9 \\
\hline \multirow{2}{*}{ Meta 3} & $3 A$ & 100 & 84,3 & 85 & 83,2 & 100 & 80,4 \\
\hline & $3 B$ & 85 & 55,3 & 85 & 53,4 & 85 & 58,4 \\
\hline \multirow{3}{*}{ Meta 5} & $5 \mathrm{~A}$ & 0 & 22,2 & 5 & 15 & 25 & 33,4 \\
\hline & $5 B$ & 0 & 34,5 & 20 & 39,1 & 46 & 53,7 \\
\hline & $5 \mathrm{C}$ & 0 & 57,1 & 45 & 51,3 & 60 & 72 \\
\hline \multirow{2}{*}{ Meta 6} & $6 \mathrm{~A}$ & 25 & 13,5 & 25 & 18,7 & 50 & 27 \\
\hline & $6 \mathrm{~B}$ & 50 & 44,2 & 51 & 50,8 & 50 & 64,7 \\
\hline \multirow{3}{*}{ Meta $7^{*}$} & $7 \mathrm{~A}$ & 6 & 5,2 & 6 & 5,2 & 6 & 4,5 \\
\hline & $7 \mathrm{~B}$ & 5,5 & 4,2 & 5 & 4,4 & 6 & 3,9 \\
\hline & $7 \mathrm{C}$ & 5,2 & 3,7 & 5 & 3,6 & - & - \\
\hline \multirow{2}{*}{ Meta 9} & $9 \mathrm{~A}$ & 93,5 & 91,5 & 90 & 83,3 & 93,5 & 77,1 \\
\hline & $9 \mathrm{~B}$ & 15 & 29,4 & 29 & 39,1 & 93,5 & 34,1 \\
\hline Meta 10 & 10 & 25 & 2,5 & 10,5 & 6,5 & 25 & 8,5 \\
\hline \multirow{2}{*}{ Meta $11^{* *}$} & $11 \mathrm{~A}$ & 4.808 .838 & 1.602 .946 & 63.081 & 63.081 & 1.268 & 845 \\
\hline & 11B & 2.503 .495 & 900.519 & 46.074 & 46.074 & 1.200 & 845 \\
\hline
\end{tabular}

*7A, 7B e 7C - representam Média do IDEB nos anos iniciais, finais do Ensino fundamental e no Ensino Médio, respectivamente.

**11A e 11B - representam Número absoluto de matrículas em educação profissional técnica de nível médio total e na rede pública respectivamente.

Fonte: Elaboração dos autores com base nos dados da pesquisa (2017).

Tecnicamente, a meta 1 se encontra parametrizada por dois indicadores: o Indicador $1 \mathrm{~A}$, que define o Percentual da população de 4 e 5 anos que frequenta a escola, e o Indicador $1 \mathrm{~B}$, que permite informar o Percentual da população de 0 a 3 anos que frequenta a escola, ambos abrangem o Brasil, grandes regiões e unidades da Federação (BRASIL, 2016b).

Segundo UNESCO (2015), cerca de 58 milhões de crianças estão fora da escola no mundo e cerca de 100 milhões de crianças não completarão a educação primária. A desigualdade na educação aumentou, com os mais pobres e desfavorecidos carregando o maior fardo.

A meta 1 do PME se coaduna com os objetivos 1 e 2 do Relatório de Monitoramento Global de Educação para Todos - 2015, que versam, respectivamente: sobre Educação e cuidados na primeira infância, visando expandir e melhorar educação e cuidados na primeira infância, principalmente para as crianças mais vulneráveis e em situação desfavorável; e 
sobre Educação primária universal, buscando garantir que, até 2015, todas as crianças, principalmente meninas, crianças em circunstâncias difíceis e as pertencentes a minorias étnicas, tenham acesso a uma educação primária completa, gratuita, obrigatória e de boa qualidade.

Para a meta 2, o município de Quixadá apresenta uma posição confortável no indicador 2A (Percentual da população de 6 a 14 anos que frequenta a escola), no entanto, os índices de repetência podem ser fatores que desencadeiam um percentual de $71,9 \%$, para uma expectativa de $95,8 \%$ de pessoas de 16 anos com pelo menos o Ensino fundamental concluído, que compõe o indicador 2B. Outro fator a se considerar é o da Evasão, esses assuntos requerem maiores aprofundamentos e poderão compor novos objetos de estudos futuros.

Os indicadores 5A, 5B e 5C representam o percentual de Estudantes com proficiência insuficiente em leitura (nível 1 na Escala de Proficiência), Escrita (níveis 1, 2 e 3 da escala de Proficiência) e Matemática (níveis 1 e 2 da escala de Proficiência), respectivamente. Percebase aqui que o alcance das metas significa reduzir os valores dos indicadores, não significando, portanto, que os valores alcançados para esses indicadores representem sucesso no município de Quixadá, por serem maiores que os valores esperados. Tais indicadores se relacionam à Avaliação Nacional da Alfabetização (ANA), desenvolvida pelo Inep para aferir os níveis de alfabetização e letramento em língua portuguesa (leitura e escrita) e matemática, alcançados pelos estudantes ao final do terceiro ano do ensino fundamental, nos municípios, nos estados e no Brasil (BRASIL, 2015).

Segundo estão apresentados os dados para o indicador $5 \mathrm{~A}$, a meta para o município é de $25 \%$, necessitando ainda rebaixamento de "oito pontos, quatro pontos percentuais", considerando os $33,4 \%$ alcançados no período.

Saliente-se aqui que, segundo dados do 'InepData - Consulta de Informações Educacionais', em 2014, "[...] para atender a uma determinação do Plano Nacional de Educação - PNE (Lei 13.005/2014), tiveram resultados divulgados as escolas que apresentaram taxa igual ou maior a $80 \%$ de participação dos estudantes" (BRASIL, 2014). Desse modo, para o ano de 2014, para o Município de Quixadá, segundo dados apresentados pelo InepData, havia uma quantidade de 20 escolas previstas para participação da pesquisa. Todas as 20 escolas participaram e todas tiveram o resultado divulgado, portanto, todas tiveram um rendimento acima de $80 \%$.

A Meta 7 é mensurada por meio dos indicadores 7A, 7B e 7C, que representam, respectivamente, média do IDEB nos anos iniciais e nos anos finais do ensino fundamental $\mathrm{e}$ do ensino médio.

Os quadros a seguir apresentam notas observadas e as metas projetadas para IDEB para o Município de Quixadá nos anos de 2007 a 2021 (a intervalos de dois anos), nos anos iniciais ( $4^{\circ}$ e $5^{\circ}$ anos) e nos anos finais ( $8^{\circ}$ e $9^{\circ}$ anos) do ensino fundamental.

\section{Quadro 2 - IDEB Município Quixadá no $4^{\circ}$ e $5^{\circ}$ anos}

\begin{tabular}{|l|c|c|c|c|c|c|c|c|c|}
\hline & $\mathbf{2 0 0 5}$ & $\mathbf{2 0 0 7}$ & $\mathbf{2 0 0 9}$ & $\mathbf{2 0 1 1}$ & $\mathbf{2 0 1 3}$ & $\mathbf{2 0 1 5}$ & $\mathbf{2 0 1 7}$ & $\mathbf{2 0 1 9}$ & $\mathbf{2 0 2 1}$ \\
\hline Metas Projetadas & - & 3.4 & 3.8 & 4.2 & 4.5 & 4.8 & 5.1 & 5.3 & 5.6 \\
\hline IDEB Observado & 3.4 & 3.9 & 4.2 & 4.4 & 4.5 & 5.3 & - & - & - \\
\hline
\end{tabular}


Quadro 3 - IDEB Município Quixadá no $8^{\circ}$ e $9^{\circ}$ anos

\begin{tabular}{|l|c|c|c|c|c|c|c|c|c|}
\hline & $\mathbf{2 0 0 5}$ & $\mathbf{2 0 0 7}$ & $\mathbf{2 0 0 9}$ & $\mathbf{2 0 1 1}$ & $\mathbf{2 0 1 3}$ & $\mathbf{2 0 1 5}$ & $\mathbf{2 0 1 7}$ & $\mathbf{2 0 1 9}$ & $\mathbf{2 0 2 1}$ \\
\hline Metas Projetadas & 3.3 & 3.4 & 3.7 & 4.1 & 4.5 & 4.7 & 5.0 & 5.3 & 3.3 \\
\hline IDEB Observado & 3.3 & 3.6 & 3.6 & 3.5 & 3.9 & 4.4 & - & - & - \\
\hline
\end{tabular}

Fonte: Brasil (2005-2015).

Observa-se que o município de Quixadá apresentou, em todas as suas séries, uma nota do IDEB, no $4^{\circ}$ e $5^{\circ}$ anos (anos iniciais do ensino fundamental), acima das metas propostas pelo índice, e, no entanto, se for considerada a Meta apresentada pelo PNE/PME, que é de 6 , para o período, o município incorrerá em posicionamento aquém da meta objetivada. $\mathrm{O}$ mesmo se observa, porém de forma mais acentuada, quando se analisam os dados obtidos do IDEB nos anos finais do ensino fundamental, pois tais metas não foram alcançadas nem no que propunha o referido índice, ficando abaixo das expectativas em todos os anos da série.

\section{Considerações Finais}

Muitas observações poderiam ser feitas sobre os dados apresentados. Contudo, serão considerados apenas os aspectos relacionados às metas do PME voltadas ao atendimento ao ensino básico, aspectos tidos como principais para o âmbito municipal.

Não se pode aqui desconsiderar que a proposta levada a cabo na Meta 1 leva em consideração apenas a educação infantil, de 0 a 5 anos, momento em que a criança (educando) requer um atendimento em infraestrutura particularmente diferenciado das demais séries e que o atendimento dessa meta perpassa por solução de problemas que, segundo aporta Oliveira (2016, p. 64), “[...] a qualidade do atendimento educacional voltado à população de zero a seis anos de idade, em várias de suas dimensões, vem sendo tema de pesquisas e debates no Brasil há mais de trinta anos", todavia, o conjunto de informações disponíveis nos censos é bastante limitado, tendo em vista os parâmetros básicos do MEC para creches e pré-escolas.

Sobre o problema do atendimento à educação infantil, Oliveira (2016, p. 63) afirma que:

Dados dos Censos Escolares de 2007 e 2014 demonstram um crescimento do número de unidades educacionais públicas com atendimento voltado às crianças de zero a três anos de idade. Também são observadas melhorias das condições materiais destes estabelecimentos, apesar das diferenças, principalmente, entre zonas, urbana e rural.

Em Quixadá, a meta 1, segundo os dados informados, apresenta $91 \%$ de concretização, cuja expectativa é de $100 \%$, para o indicador 1a o alcance é de $28,2 \%$, para expectativa de $50 \%$, e, em comparação com as metas nacional e estadual (do Ceará) apresentadas, o município se encontra em condições favoráveis.

Considerando a relevância de todos os indicadores para os objetivos propostos pelo PNE e pelo PME, pode-se depreender, sem prescindir da importância dos demais, que os indicadores da Meta 5 representam significativo pré-requisito a outros indicadores, pois se relaciona à capacidade de entendimento daquilo que se lê, principalmente, como reforça Ribeiro (1997, p. 150), quando afirma que "[...] o valor do acesso à leitura e à escrita reside também no fato de serem meios para se aprender outras habilidades, ampliando a autonomia das pessoas com relação ao auto aprendizado e à educação continuada". Trata-se, portanto, de um dos pressupostos basilares para educação: ler e entender o que se está lendo, ser 
capaz de inferir, deduzir, manifestar conclusões e criar novos pensamentos que conduzam o indivíduo ao crescimento cognitivo.

Em relação às estratégias do PME, em seu artigo $11^{\circ}$, o PME prevê que o cumprimento das metas e estratégias está condicionado ao aumento das transferências de recursos financeiros e de outras naturezas do Governo Federal, de acordo com seu papel redistributivo, supletivo e colaborativo, assim como estabelecido no Artigo 211 da Constituição Federal e Artigo $9^{\circ}$ da Lei de Diretrizes e Bases da Educação Nacional - LDB 9394/96. Nesse ponto, observa-se uma possível vulnerabilidade no andamento e continuidade do PNE e PME, considerando que, como já foi aportado, a redução dos gastos prevista na Proposta de Emenda Constitucional - PEC n 55/2016, em tramitação no Senado, se aprovada, impedirá o cumprimento das metas estabelecidas no Plano Nacional de Educação (PNE) em todo o território nacional.

O Artigo 15 prevê ainda que as despesas decorrentes do PME corram a expensas das dotações orçamentárias da Secretaria Municipal de Educação, alocadas e remanejadas mediante decretos executivos, regulamentando a movimentação de dotações e verbas, autorizando a abertura de créditos adicionais suplementares, especiais e a realização de outras alterações necessárias com a finalidade de adequação ao PME.

Sobre esse contexto, o Documento Norteador para Elaboração de Plano Municipal de Educação - PME propõe que:

A análise dos recursos financeiros aplicados na educação fornecerá uma visão das possibilidades de realização das ações necessárias à melhoria da educação no município. Sem os recursos financeiros indispensáveis, as metas do plano não poderão ser alcançadas. É preciso ter preocupação em garantir os recursos para todas as despesas do plano no decorrer dos anos de sua vigência. Este é o momento de verificar se o município terá condições de concretizar as propostas do PME e de observar se os mecanismos de financiamento previstos estão condizentes com a legislação vigente e o PNE (BRASIL, 2005, p. 71).

A despeito das previsões de corte orçamentário que restringiriam a conquista das metas estabelecidas do PME, em seu Artigo 15, incisos I, II e III, há previsão de realocação de recursos a partir de créditos adicionais, especiais ou outras alterações que sejam necessárias com o fim de adequação à lei, no entanto não se especificam suas origens.

Vale lembrar que o art. 68 da LDB lista as fontes de recursos públicos para a educação e o art. 69 da própria LDB, baseado no art. 212 da CF, estabelece que os municípios devam aplicar 25\% (ou o que constar na Lei Orgânica do Município) de sua receita própria na manutenção e desenvolvimento do ensino público. Ademais, a Emenda Constitucional $n^{\circ}$ 14/96 criou o Fundef, por meio do qual os recursos também são redistribuídos entre os estados e os municípios, de forma proporcional ao número de alunos matriculados no ensino fundamental, de acordo com o custo padrão anual por aluno ano, definido pelo MEC.

Existe ainda uma previsão de renovação do PME, para o próximo decênio (2025-2035), contemplada em seu artigo 13, cujas metas serão balizadas pelos dados oferecidos pelo PNE 2015-2025.

Sabe-se que a busca pela equidade e pela qualidade da educação em um país tão desigual como o Brasil é uma tarefa que implica políticas públicas de Estado que incluam uma ampla articulação entre os entes federativos. Vive-se um momento fecundo de possibilidades, 
Análise das Metas do Plano Municipal de Educação de Quixadá-CE à Luz do PNE, da Legislação e do Documento Norteador

com bases legais avançadas e com a mobilização estratégica dos setores públicos e de atores sociais importantes neste cenário. A proposta trazida no contexto do diagnóstico, do planejamento, da elaboração e na previsão de execução do Plano Nacional de Educação manifesta uma clara maturidade política no trato com as políticas públicas voltadas para educação, porém, não se garante que com o atual PNE a história seja diferente.

Nenhum plano nasce pronto, tampouco é capaz de satisfazer os anseios de todos os seguimentos sociais, tendo em vista que, a despeito das contraditas, a governança é imprescindível, assim "[...] os governos têm a responsabilidade principal de cumprir com o direito à educação e desempenham um papel central como guardiões do gerenciamento e do financiamento eficiente, equitativo e eficaz da educação pública" (BRASIL, 2016c, p. 27). Melhorar a governança e a responsabilização pode aumentar a eficiência e a eficácia do uso dos recursos existentes e garantir que o financiamento chegue até a sala de aula.

\section{Referências}

ANDRIOLA, Wagner Bandeira. Evaluación: La vía para la calidad educativa. Ensaio. Avaliação e Políticas Públicas em Educação, Rio de Janeiro, v. 7, n. 25, p. 355-368, 1999.

BANDEIRA, Claudia et al. O Uso dos Indicadores da Qualidade na Educação na Construção e Revisão Participativas de Planos. São Paulo: Ação Educativa, 2013. 32 p. (Coleção De Olho nos Planos).

BLASQUES, Cynthia Neves. A Educação do Século XXI e as Competências da Sociedade do Conhecimento e da Aprendizagem. In: SIMPÓSIO INTERNACIONAL DE EDUCAÇÃO A DISTÂNCIA, 3., 2016, São Carlos. Anais... São Carlos: UFSCAR, 2016. p. 1-15. Disponível em: <https://goo.gl/mlb6O9>. Acesso em: 09 dez. 2016.

BRASIL. Constituição (1988). Constituição da República Federativa do Brasil de 1988. Diário Oficial da União, Brasília, 05 out. 1988.

BRASIL. Lei $n^{\circ}$ 9394, de 20 de dezembro de 1996. Estabelece as diretrizes e bases da educação nacional. Diário Oficial da União, Brasília, DF, 23 dez. 1996. P. 27833.

BRASIL. Emenda Constitucional ${ }^{\circ} 59$, de 11 de novembro de 2009. Diário Oficial da União, Brasília, DF, 12 nov. 2009.

BRASIL. Diretoria de Estudos Educacionais (Dired). Instituto Nacional de Estudos e Pesquisas Educacionais Anísio Teixeira (INEP). PNE em Movimento: Construindo Indicadores Educacionais nos municípios. Brasília: Inep, 2016a. Disponível em: <https://goo.gl/zpMES8>. Acesso em: 29 nov. 2016.

BRASIL. IBGE - Instituto Brasileiro de Geografia e Estatística. Secretaria do Planejamento e Gestão do Governo do Estado do Ceará. Cidades. 2013. Disponível em: <http://cod.ibge.gov.br/5NF>. Acesso em: 05 dez. 2016.

BRASIL. INEP - Instituto Nacional de Estudos e Pesquisas Educacionais Anísio Teixeira. Plano Nacional de Educação PNE 2014-2024: Linha de Base. Brasília, 2015. 404 p. Disponível em: <https://goo.gl/g8F7Km>. Acesso em: 28 nov. 2016. 
BRASIL. Lei n 13.005, de 25 de junho de 2014. Aprova o Plano Nacional de Educação - PNE e dá outras providências. Diário Oficial da União, Brasília, DF, 25 jun. 2014a. Disponível em: <https://goo.gl/Eylri7 >. Acesso em: 28 nov. 2016.

BRASIL. Ministério da Educação. INEP - Instituto Nacional de Estudos e Pesquisas Educacionais Anísio Teixeira. IDEB - Índice de desenvolvimento da Educação Básica: Resultados e Metas. 2005-2015. Atualizado em: 05 set. 2016. Disponível em: $<$ http://ideb.inep.gov.br/resultado/resultado/resultado.seam?cid=3899242>. Acesso em: 06 dez. 2016.

BRASIL. Ministério da Educação. INEP - Instituto Nacional de Estudos e Pesquisas Educacionais Anísio Teixeira. InepData: consulta de informações educacionais. 2014. Pesquisa aplicada de 17 a 28 de novembro de 2014. Disponível em: <http://ana.inep.gov.br/ANA/>. Acesso em: 09 dez. 2016.

BRASIL. Ministério da Educação. Márcia Angela da Silva Aguiar. Planejando a Próxima Década: Conhecendo as 20 Metas do Plano Nacional de Educação. Brasília: MEC, 2014b. 62 p. Disponível em: <https://goo.gl/dRiWXW>. Acesso em: 01 dez. 2016.

BRASIL. Ministério da Educação. Presidência da República. Monitoramento e Avaliação dos Planos de Educação. Brasília, 2016b. Disponível em: <https://goo.gl/WIHI6L>. Acesso em: 07 dez. 2016.

BRASIL. Ministério da Educação. Secretaria de Educação Básica. Clodoaldo José de Almeida Souza. Documento Norteador para Elaboração de Plano Municipal de Educação - PME. Brasília: Secretaria de Educação Básica, 2005. 98 p.

BRASIL. UNESCO. Educação 2030 Declaração de Incheon: rumo a uma educação de qualidade inclusiva e equitativa e à educação ao longo da vida para todos. Brasília: UNESCO, 2016c. Disponível em: <https://goo.gl/qjCPL9>. Acesso em: 07 dez. 2016.

CEARÁ. Comissão de Normalização. Biblioteca Universitária UFC (Org.). Guia de Normalização de Trabalhos Acadêmicos da UFC. Fortaleza: Biblioteca Universitária, 2013. 173 p. Disponível em: <https://goo.gl/8fJkgJ>. Acesso em: 06 dez. 2016.

CEARÁ. Instituto de Pesquisa e Estratégia Econômica do Ceará (IPECE). Secretaria do Planejamento e Gestão (SEPLAG). Perfil Básico Municipal - 2015 - Quixadá. 2015. Disponível em: <https://goo.gl/8Gyjwr>. Acesso em: 05 dez. 2016.

DOURADO, Luiz Fernandes. Políticas e Gestão da Educação Básica no Brasil: limites e perspectivas. Educação \& Sociedade, Campinas, v. 28, n. 100, p. 921-946, out. 2007.

EDITORES, Revista Educação \& Sociedade. O Contexto Político e a Educação Nacional Editorial. Educação \& Sociedade, Campinas, v. 37, n. 135, p. 329-334, jun. 2016. Disponível em: <http://dx.doi.org/10.1590/es0101-73302016v37n135ed>. Acesso em: 23 dez. 2016.

FRIGOTTO, Gaudêncio; CIAVATTA, Maria. Educação Básica no Brasil na Década de 1990: subordinação ativa e consentida à lógica do mercado. Educação \& Sociedade, Campinas, v. 24, n. 82, p. 93-130, abr. 2003.

GIL, Antonio Carlos. Como Elaborar Projetos de Pesquisa. 5. ed. São Paulo: Atlas, 2010. $184 \mathrm{p}$. 
HENTZ, Paulo. O Plano Nacional de Educação e suas Consequências nos Estados e nos Municípios. Roteiro, Joaçaba, ed. especial, n. 1, p. 131-144, 15 nov. 2014.

HÖFLING, Eloisa de Mattos. Estado e Políticas (Públicas) Sociais. Cadernos Cedes, Campinas, v. 21, n. 55, p. 30-41, nov. 2001.

MARCONI, Marina de Andrade; LAKATOS, Eva Maria. Fundamentos de Metodologia Científica. 7. ed. São Paulo: Atlas, 2010. 320 p.

OLIVEIRA, Regina Tereza Cestari de. A QUALIDADE DA EDUCAÇÃO BÁSICA NO CONTEXTO BRASILEIRO: ASPECTOS HISTÓRICOS. In: SEMINÁRIO NACIONAL DE ESTUDOS E PESQUISAS "HISTÓRIA, SOCIEDADE E EDUCAÇÃO NO BRASIL", 9., 2012, João Pessoa. Anais Eletrônicos. João Pessoa - Pb: Ufpb, 2012. p. 2797 - 2812.

OLIVEIRA, Tiago Grama de. As condições das creches públicas e conveniadas com o poder público no Brasil. Revista Ibero-americana de Educação, Araraquara, v. 71, p. 63-86, 2016.

PRODANOV, Cleber Cristiano; FREITAS, Ernani Cesar de. Metodologia do Trabalho Científico [recurso eletrônico]: Métodos e Técnicas da Pesquisa e do Trabalho Acadêmico. 2. ed. Novo Hamburgo: Universidade Feevale, 2013. 276 p. Disponível em: <https://goo.gl/Aofck1>. Acesso em: 23 maio 2016.

QUIXADÁ (Município). Lei no 2755, de 19 de junho de 2015. Aprova o Plano Municipal de Educação de Quixadá para o Decênio 2015 a 2025 e dá outras providências. Plano Municipal de Educação de Quixadá. Quixadá, CE, 2015b. Disponível em: <https://goo.gl/clNIcL>. Acesso em: 28 nov. 2016.

QUIXADÁ (Município). Portaria n 001, de 10 de setembro de 2013. Cria o Fórum Municipal de Educação para coordenar a elaboração do Plano Municipal de Educação de Quixadá e dá outras providências. Portaria Gabinete 001/2013. Quixadá, CE, 2013a. Disponível em: <https://goo.gl/aKFGm0>. Acesso em: 06 dez. 2016.

QUIXADÁ (Município). Portaria ${ }^{\circ}$ 002, de 10 de setembro de 2013. Nomeia a comissão do Plano Municipal de Educação para o decênio 2015 a 2025 e dá outras providências. Portaria Gabinete 002/2013. Quixadá, CE, 2013b. Disponível em: <https://goo.gl/BF9eOH>. Acesso em: 06 dez. 2016.

QUIXADÁ (Município). Portaria $n^{\circ} 35 / 2014$, de 30 de julho de 2014. Institui a Comissão Representativa da Sociedade para Elaboração/Adequação do Plano Municipal de Educação do Município de Quixadá-Ce. Portaria Gabinete 035/2014. Quixadá, CE, 2014. Disponível em: <https://goo.gl/hc3Rfv>. Acesso em: 06 dez. 2016.

QUIXADÁ. Câmara Municipal de Quixadá. 19.06.15 - Câmara discute Plano Municipal de Educação. Quixadá, CE, 2015a. Disponível em: <https://goo.gl/rRVLSV>. Acesso em: 06 dez. 2016.

RIBEIRO, Vera Masagão. Alfabetismo funcional: referências conceituais e metodológicas para a pesquisa. Educação \& Sociedade, Campinas, v. 18, n. 60, p. 144-158, 1997.

SOUZA, Donaldo Bello de; BATISTA, Neusa Chaves. Balanço das Avaliações Municipais do Plano de Ações Articuladas: desafios atuais ao desenvolvimento da política nacional PAR. Educação em Revista, Belo Horizonte, v. 32, n. 1, p. 105-131, mar. 2016. 
Análise das Metas do Plano Municipal de Educação de Quixadá-CE à Luz do PNE, da Legislação e do Documento Norteador

UNESCO. Educação 2030 - Declaração de Incheon: Rumo a uma educação de qualidade inclusiva e equitativa e à educação ao longo da vida para todos. Brasília: UNESCO, 2016. 53 p. Disponível em: <https://goo.gl/6S4UgT>. Acesso em: 07 dez. 2016.

UNESCO; ONU (Org.). Relatório de Monitoramento Global de Educação para Todos 2015: progressos e desafios. Paris: Unesco Publishing, 2015. 55 p. Relatório Conciso. Disponível em: <https://goo.gl/Aas3f9>. Acesso em: 07 dez. 2015.

VALLE, Bertha de Borja Reis do. O PNE e o PDE como desafios políticos para os educadores. Revista Tessituras, Nova Friburgo, Edição Zero, p. 1-14, 2009. Disponível em: <https://goo.gl/LgkJ67>. Acesso em: 29 nov. 2016.

VIANNA, Heraldo Marelim. Fundamentos de um Programa de Avaliação Educacional. Brasília: Liber Livro Editora, 2005. 182 p.

YIN, Robert K. Estudo de Caso: planejamento e métodos. 4. ed. Porto Alegre: Bookman, 2010.

Antônio Jones Bezerra de Almeida é aluno do Curso de Mestrado em Políticas Públicas e Gestão da Educação Superior pela Universidade Federal do Ceará (UFC), Especialista em Gestão Escolar e Coordenação Pedagógica pela Faculdade Kurios, Licenciado em Ciências Biológicas pela Universidade Estadual do Ceará.

E-mail: almeida.ufc.2010@gmail.com

Sueli Maria de Araújo Cavalcante é doutora em Educação, pela Faculdade de Educação da Universidade federal do Ceará (FACED/UFC).

E-mail: suelicavalcante@hotmail.com

Alberto Sampaio Lima é doutor em Engenharia de Teleinformática pela Universidade Federal do Ceará. Mestre em Informática Aplicada pela Universidade de Fortaleza. Professor Adjunto da Universidade Federal do Ceará.

E-mail: alberto.ufc@gmail.com

Linnik Israel Lima Teixeira é mestrando em Políticas Públicas e Gestão da Educação Superior, Graduação em Administração pela Universidade Federal do Ceará.

E-mail: linnik.lima@gmail.com

Recebido em 04 de outubro de 2017

Aprovado em 31 de janeiro de 2018 


\title{
Editores do volume 8
}

José Marcelino de Rezende Pinto - Universidade de São Paulo, São Paulo/SP, Brasil

Nalú Farenzena - Universidade Federal do Rio Grande do Sul, Porto Alegre/RS, Brasil

\section{Comitê Editorial}

José Marcelino de Rezende Pinto - Universidade de São Paulo, Brasil

Juca Gil - Universidade Federal do Rio Grande do Sul, Brasil

Theresa Adrião - Universidade Estadual de Campinas, Brasil Ângelo

Ricardo de Souza - Universidade Federal do Paraná, Brasil

Márcia Aparecida Jacomini - Universidade Federal de São Paulo, Brasil

\section{Conselho Editorial}

\section{Alejandro Morduchowicz}

Universidad Pedagógica, Provincia de Buenos Aires, Argentina

Fernanda Saforcada

Universidade de Buenos Aires, Argentina

Jacques Velloso

Universidade de Brasília, Brasil

João Monlevade

Senado Federal, Brasil

Jorge Abrahão de Castro

Instituto de Pesquisa Econômica Aplicada / IPEA, Brasil

Juca Gil

Universidade Federal do Rio Grande do Sul, Brasil

Lisete Regina Gomes Arelaro

Universidade de São Paulo, Brasil

Luis Carlos Sales

Universidade Federal do Piauí, Brasil

Luiz de Sousa Junior

Universidade Federal da Paraíba, Brasil

Luiz Fernandes Dourado

Universidade Federal de Goiás, Brasil

Magna França

Universidade Federal do Rio Grande do Norte, Brasil

\section{Maria Beatriz Luce}

Universidade Federal do Pampa, Brasil

Universidade Federal do Rio Grande do Sul, Brasil

Marcos Edgar Bassi

Universidade Federal do Paraná, Brasil

\author{
Maria Dilnéia Espíndola Fernandes \\ Universidade Federal de Mato Grosso do Sul, Brasil \\ Nalú Farenzena \\ Universidade Federal do Rio Grande do Sul, Brasil \\ Nelson Cardoso do Amaral \\ Universidade Federal de Goiás, Brasil \\ Nicholas Davies \\ Universidade Federal Fluminense, Brasil \\ Rosana Evangelista Cruz \\ Universidade Federal do Piauí, Brasil \\ Rosana Gemaque \\ Universidade Federal do Pará, Brasil \\ Robert E. Verhine \\ Universidade Federal da Bahia, Brasil \\ Romualdo Portela de Oliveira \\ Universidade de São Paulo, Brasil \\ Theresa Adrião \\ Universidade Estadual de Campinas, Brasil \\ Tristan McCowan \\ University of London, Reino Unido \\ Vera Jacob \\ Universidade Federal do Pará, Brasil \\ Vera Peroni \\ Universidade Federal do Rio Grande do Sul, Brasil \\ Vitor Henrique Paro \\ Universidade de São Paulo, Brasil
}

\section{Equipe editorial}

Apoio ao Comitê Editorial: Patrícia Balthazar Garcia

Diagramação, Revisão de português e normalização: Edson Leonel de Oliveira

Revisão de inglês: Ananyr Porto Fajardo 